\title{
The position of land use planning in the cropping pattern design
}

\section{Editorial}

Management is one of the most important options that determine the function of agricultural ecosystems. Sometimes when we talk about management options, some options such as varieties, seeding rate, planting dates, planting densities, and so forth are passing through our minds immediately. But the reality is that perhaps the most important management is managing of those factors that unintentionally affect our ecosystems, and sometimes we ignore them. Sometimes we do our best to give proper external inputs, control weeds well or control pests with spraying and so on. The fact is that sometimes the problem must be overcome and the type of managerial viewpoint should be changed. I believe that a farm manager should be an ecologist in the first place, because if I want to manage my agro-ecosystem, I want to know well about its components. In this regard, the good director is a manager who, from the outset, provides the conditions that the plant needs in order to grow under optimal conditions, with less costly management. Accordingly, management can be interpreted in two ways. First the management that should be done after the formation of the agroecosystems. These managements are based on the apparent state of the agro-ecosystem or laboratory observations, but these administrations do not affect the potential of their agro-ecosystem and only help reduce the gap between actual production and potential production or, in other words, reduce the yield gap. But the reality is that the potential production of different areas is not the same, and a plant may be cultivated in a region where its potential production is inherently low. For example, in areas where radiation flux density is low or in spite of the high intensity of radiation, there are few sunny hours, the potential for production is not so high and it cannot even be achieved under high intensive management. Therefore, in these areas, there should be other plants in the cropping patterns. Therefore, it seems that crop arrangement in agro-ecosystems should be made conscious. Accordingly, the second category of management involves the largescale management, which means that the manager decides whether or not to have a crop in a particular area, not what a fertilizer will give or how much seed they will use. Determining these management strategies requires reliable and long-term information and, on the other hand, the ecosystem's power needs to be assessed for the target. The first step in designing cropping patterns is the choice of plant type. The question that arises here is what crops should be considered in cropping patterns. This topic has been discussed in my previous editorial manuscript entitled "Cropping patterns: some points need to point", but this editorial will be considered in a different perspective. In this manuscript we will pay attention to "whether or not a particular crop has the potential for proper production in a target cropping pattern? In this way, some crops may be quite desirable or some crops are completely undesirable, but there may be different possibilities for cultivation in one area. Therefore, if the suitability analysis for planting a given crop shows different suitability classes (varying from favorable to limiting), determining the priorities for planting in agro-ecosystems is possible. Undoubtedly, in cropping patterns, those crops with higher suitability will place in the top priority of selection. Therefore, a crop that has very favorable conditions for the cultivation in one region may not be placed in a priority for cultivation in another place. Therefore, setting these priorities is actually a basic filter for
Volume 7 Issue 3 - 2017

\author{
Behnam Kamkar \\ Department of Agronomy, Gorgan University of Agricultural \\ Sciences and Natural Resources (GUASNR), Iran
}

Correspondence: Behnam Kamkar, Associate professor, Department of Agronomy, Gorgan University of Agricultural Sciences and Natural Resources (GUASNR), Iran, Tel +989| |2734|53, +98-17-324376 I5,

Email behnam.kamkar@gmail.com

Received: July 24, 2017 | Published: July 25, 2017

entering to ecosystem design and needs to be done carefully.

Land use planning in the general sense, and agriculture and the natural resource planning in its particular sense, are the first requirement for successful design of appropriate cropping patterns. In this way, regional capabilities are examined for climate, soil, topography and even critical events. In this way, because we use overlaying and querybased analysis, the outputs will be very valuable on the condition of the accuracy of the basic data. Land use planning is a plan that helps planners and policy makers in the agricultural and natural resources sector in deciding on the presence or absence of a plant in a cropping pattern or other development plans in the field of natural resources management. In fact, land use allows the optimal use of environmental facilities and makes farmers more confident in thinking the first type of management. So, in general, the agro-ecosystems should look from top to down so that they can be considered comprehensive. Therefore, it is recommended that researchers in the agricultural field plan for precise agricultural land use planning, find optimal methods, and ultimately provide user maps. Undoubtedly, the publication of these findings in the form of data in the coordinates on the global network (Web GIS- projects) can also help to increase the general knowledge of users and facilitate the decision making of managers. Therefore, it seems that future studies in this regard will be directed or, at least, it will be necessary to move towards land use planning-based studies. Undoubtedly, studies at large- and ecosystem-scale levels are closer to the reality of the system, because of the interaction between all of involved factors, and this can have an impact on the probable success of agro-ecosystems. Therefore, the second category of management is knowledge-based management, and researchers' knowledge of the environment and information overlap can be a good initial filter for crop selection in cropping patterns. The conscious selection of crops in cropping patterns can provide the correct arrangement of these crops at a time and place, which is one of the important steps to achieve efficient agro-ecosystems.

\section{Acknowledgements}

None.

\section{Conflict of interest}

The author declares no conflict of interest. 